\title{
Embedding anti-counterfeiting features in metallic components via multiple material additive manufacturing
}

DOI:

10.1016/j.addma.2018.09.003

\section{Document Version}

Accepted author manuscript

Link to publication record in Manchester Research Explorer

\section{Citation for published version (APA):}

Wei, C., Sun, Z., Huang, Y., \& Li, L. (2018). Embedding anti-counterfeiting features in metallic components via multiple material additive manufacturing. Additive Manufacturing, 24, 1-12.

https://doi.org/10.1016/j.addma.2018.09.003

\section{Published in:}

Additive Manufacturing

\section{Citing this paper}

Please note that where the full-text provided on Manchester Research Explorer is the Author Accepted Manuscript or Proof version this may differ from the final Published version. If citing, it is advised that you check and use the publisher's definitive version.

\section{General rights}

Copyright and moral rights for the publications made accessible in the Research Explorer are retained by the authors and/or other copyright owners and it is a condition of accessing publications that users recognise and abide by the legal requirements associated with these rights.

\section{Takedown policy}

If you believe that this document breaches copyright please refer to the University of Manchester's Takedown Procedures [http://man.ac.uk/04Y6Bo] or contact uml.scholarlycommunications@manchester.ac.uk providing relevant details, so we can investigate your claim.

\section{OPEN ACCESS}




\section{Manuscript Details}

\section{Manuscript number}

Title
ADDMA_2018_503_R1

Embedding Anti-counterfeiting Features in Metallic Components via Multiple Material Additive Manufacturing

Research Paper

\section{Article type}

Abstract

The aerospace, automotive and medical industries are suffering from significant number of counterfeited metallic products that not only have caused financial losses but also endanger lives. The rapid development of additive manufacturing technologies makes such a situation even worse. In this investigation, we successfully applied a novel hybrid powder delivery selective laser melting (SLM) approach to embed dissimilar tagging material (Cu10Sn copper alloy) safety features (e.g. QR code) into metallic components made of $316 \mathrm{~L}$ stainless steel. X-ray imaging was found to be a suitable method for the identification of the embedded safety features up to $15 \mathrm{~mm}$ in depth. X-ray fluorescence was used for the chemical composition identification of the imbedded security tagging material. A criterion for the selection of tagging material, its dimensions and imbedding depth is proposed. The multiple material SLM technology was shown to offer the potential to be integrated into metallic component production for embedding anti-counterfeiting features.

\section{Keywords}

Corresponding Author

Corresponding Author's Institution

Order of Authors
Anti-counterfeiting; additive manufacturing; multiple-material; selective laser melting; non-destructive inspection, QR code, imbedding

Lin Li

LASER PROCESS RESEARCH CENTRE

CHAO WEI, Lin Li, ZHE SUN, YIHE HUANG

\section{Submission Files Included in this PDF}

\section{File Name [File Type]}

Cover Letter - V1.docx [Cover Letter]

Response to Reviewers Comments -ADDMA_2018_503.docx [Response to Reviewers]

Revised Manuscript - ADDMA_2018_503.docx [Manuscript File]

To view all the submission files, including those not included in the PDF, click on the manuscript title on your EVISE

Homepage, then click 'Download zip file'.

\section{Research Data Related to this Submission}

There are no linked research data sets for this submission. The following reason is given:

Data will be made available on request 


\section{Editorial Office}

Additive Manufacturing

05/08/2018

\section{Dear Editor,}

We are submitting a manuscript entitled "Embedding Anti-counterfeiting Features in Additive Manufactured Metallic Components via Multiple Material Additive Manufacturing" for consideration by 'Additive Manufacturing' Journal.

I confirm that this work is original and has not been published elsewhere nor is it currently under consideration for publication elsewhere.

The aerospace, automotive and medical industries are suffering from significant number of counterfeited metallic products that have caused financial losses and also could endanger lives. The rapid development of additive manufacturing technologies makes such a situation even worse. Until now, there has been no reported work on imbedding anti-counterfeiting features in additive manufactured metallic parts. In this investigation, we successfully applied a novel hybrid powder delivery selective laser melting (SLM) approach developed at The University of Manchester (patent pending) to embed dissimilar tagging material (Cu10Sn copper alloy) safety features into metallic components made of $316 \mathrm{~L}$ stainless steel. These features could be inspected via non-destructive inspection approaches. The results showed that X-ray imaging was the most promising method for the identification of the embedded safety features up to $15 \mathrm{~mm}$ in depth. The multiple material SLM technology was shown to offer the potential to be integrated with the block-chain technology to anti-counterfeiting of the metallic components manufactured fully or partially with additive manufacturing. The paper should be of interest to readers in the areas of aerospace, automotive, and medical industries who apply selective laser melting additive manufacturing technology for producing metallic components.

The highlights of this paper include:

- Embedding safety features made of dissimilar tagging material in the SLM processed metallic components for anti-counterfeiting purpose, not reported before.

- Applying X-ray imaging approach to examine the implanted anti-counterfeiting features in the additive manufactured metallic components successfully, reported for the first time.

- Material characteristics at the interfaces between the tagging material and the build material.

Please address all correspondence concerning this manuscript to me at: lin.li@manchester.ac.uk. Thank you for your consideration of this manuscript.

Yours Sincerely,

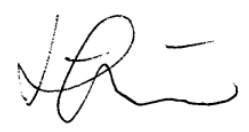

Professor Lin Li 
Manuscript Reference no: ADDMA_2018_503

Paper title: Embedding Anti-counterfeiting Features in Metallic

Components via Multiple Material Additive Manufacturing

\section{Authors' Response to Comments from the Reviewers and \\ $\underline{\text { Editors }}$}

\section{Reviewer 1}

1) Great paper really about multi-material SLM which is done well and with great resolution and this is just one of many applications for multi-material (QR code for anticounterfeiting). Can you at least describer the other motivations.

Please refer to page 3 of the revised paper:

"...... The University of Manchester demonstrated a novel ultrasonic selective powder delivery integrated into powder bed SLM [31], which showed the potential for applications for the tailoring of local material prosperities in components (e.g. medical implants), printing of mechanical-electronic integrated devices (e.g. electric motors and batteries), and creative designs (e.g. jewelries made of several types of precious metals) …..."

2) You missed a paper by Cesar Terrazas which made multi-material parts but only layer by layer (not with two materials in one layer). You should add this as a reference for multimaterial powder bed fusion although I understand your work is better with the vacuum and dispenser.

This paper has been added and cited, Please refer to page 3 of the revised paper:

"......Previous investigations on multiple metallic material additive manufacturing $[32,33]$ indicated that copper and related alloys can be bonded well with Ti6Al4V titanium alloy and $316 \mathrm{~L}$ stainless steel, and the components achieved good mechanical performances......"

3) I also thought that the multiple reading methods was interesting to show advantages and disadvantages. I think IR is more interesting as it seems to be less affected by thickness. XRAY looked great but thin features of a structure may not always be available.

It is true that IR imaging is quite attractive as we can use the small hand-held device to easily detect the security feature. However our simulation and experimental results indicate that this method could not detect the QR code embedded below the surface.

$\mathrm{X}$-ray system can detect the tag well below the surface, while the QR code thickness and X ray power intensity may need to be increased as the imbedding depth increases. 
Experimental evidences have been provided in the paper.

4) "for a long time" not very specific. Can you be more clear?

"for a long time" is deleted now. Please refer to page 2 of the revised paper:

"... ... Unfortunately, all these 3 industries are seriously suffering from the illegal counterfeits. ......"

5) degrees Celsius has a strange symbol for the $C$.

${ }^{\circ} \mathrm{C}$ is replaced by ${ }^{\circ} \mathrm{C}$.

6) "of these 5 key elements" numbers under ten should be spelled out.

The discussion about XRF data has been revised, please refer to page 18 of the revised paper:

"......All chemical elements of Cu10Sn and 316L were detected on sample A, especially the strong $\mathrm{Cu}$ signal (67.67\% in Error! Reference source not found.) from the tag material Cu10Sn. The Sn signal on sample A (7.20\%) was 21 times stronger than that of sample C (0.36\%) where Sn was covered by stainless steel layers. All the key elements (i.e. $\mathrm{Cr}$, Fe, and $\mathrm{Ni}$ ) of $316 \mathrm{~L}$ building material in sample $\mathrm{A}$ were much lower than those in the sample $\mathrm{C}$ (7.05\% / 17.53\%, 14.21\% / 61.05\%, and 2.24\% / 11.82\% respectively). Because the QR code made of Cu10Sn occupied the biggest area for the XRF examination, and the 316L material just filled the space around the pixels of the QR-code. Therefore the element radiation photons emitted by $316 \mathrm{~L}$ material was much less. ......"

7) "Tags should be imbedded with the relatively thin over by the component material as the Xray imaging resolution decreases substantially as the barrier thickness increases" ???? problem.

This was explained in the revised text with more quantified explanation. If the security features were imbedded too deep, say, $15 \mathrm{~mm}$, their identification would become more difficult and the resolution of the security features would be compromised.

8) In figure 13, I understood the tag was embedded with a layer both above and below. However, in the optical cases, I can see the QR code. Can you explain?

In figure 13a, the QR code was partially embedded - i.e. 2/3 of the QR code was imbedded below the surface and 1/3 was exposed on the surface.

9) Is there an impact to the planarization of the subsequently layer due to the code material. the ultrasonic deposited powder 
After the laser fusion of the code material and the surrounding build material in each layer, a point by point vacuum powder remover was applied to remove any access materials. For the subsequent layer deposition, the deposition head controlled the leveling of the powder deposited for the QR code, while the standard powder spread blade controlled the leveling of the build material.

\section{Reviewer 2}

The manuscript focuses on embedding provenance into metal AM parts. Authors utilized multimaterial SLM process to fabricate parts with embedded barcodes using different metal so it can be detected using X-ray imaging or other spectral techniques.

1) Paper does not demonstrate an adequate understanding of relevant literature in the field and does not cite an appropriate range of literature sources. On the contrary, authors state that no attempts have been made to embed provenance into metal AM parts (for the exception of altering CAD files). This simply is not true as academic groups (e.g. Dr. Nikhil Gupta, NYU) and industry (Infratrac) are very active in this arena. Since significant work by others has been ignored, it is not clear how author's solution is unique or different from existing approaches.

The literature review has been revised. The work of Dr. Nikhil Gupta, NYU and industry (Infratrac) was added.

Please refer to pages 2 and 3 of the revised paper:

“...... Gupta et al carried out an investigation on embedding tracking codes, i.e. Quick Response (QR) code having fast readability and greater storage capacity [16], in additive manufactured parts for product authentication [17-19], and applied a micro-CT scanner to detect the embedded QR code in polymer components comprised of black and white resin, and laser sintered single metal component made of AlSi10Mg alloy, in which the powder particle in the QR code region were not fused [18], that may cause component fatigue failure problem due to the voids created. The technical limitations of existing commercial metal additive manufacturing technologies, including powder-bed fusion and directed energy deposition would make embedding security features of a high resolution difficult.. Firstly, present commercial powder-bed fusion machine, e.g. selective laser melting (SLM) systems can only spread a single material on the same powder layer. If such a machine is used to embed the QR codes, the pixels of the QR code have to be designed as a set of voids filled with loose powder inside the solid components or a group of blind holes on the internal surface of the hollow components. Stress concentration will distribute around these small QR pixels, i.e. voids, and they can easily lead to the 3D printed component fracture under high static/dynamic loading or fatigue failure due to cyclical stress after long working period [20-22]. It is notable that the density requirement of the 3D printed metal component used in the aerospace industry is close to $100 \%$. Undesirable voids are strictly prohibited. On the other hand, multiple material metal additive manufacturing would provide an alternative solution, as dissimilar metal material having good metallurgical 
bonding with the main part material can be used as a tagging material and fill the pixel voids of $\mathrm{QR}$ code and firmly bonded with the main building material of the component after melting. The commercial directed energy deposition systems are available for multiple material metal deposition. InfraTrac company applied such multiple material system, i.e. Laser Metal Deposition (LMD), to embed a special tag into a titanium alloy part and detect it successfully with X-ray fluorescent equipment [23]. Due to the poor processing resolution of the LMD method, sub-millimeter scale along the horizontal direction [24], it is not suitable for printing the tiny pixels in the QR code. More seriously, due to the use of gas delivery of the powders in the LMD processes, some powder particles can splash to other parts leading to the contamination of the building material and the tagging material [25].

Therefore it is important to develop a high resolution multiple metallic material additive manufacturing technology to embed tracking codes as a new anti-counterfeiting approach. The embedded safety features should be easily and effectively identified by ordinary nondestructive testing approaches widely applied in industry, for instance, thermography, radiography, and fluorescent methods [26,27], and survive in the harsh working environment [28]. The resolution SLM is typically 20-50 $\mu \mathrm{m}$ [29], much higher than that of directed energy deposition approaches [30]. This makes multiple material SLM a promising method to imbed the tiny QR codes into the metallic components manufactured fully or partially with additive manufacturing. The University of Manchester demonstrated a novel ultrasonic selective powder delivery integrated into powder bed SLM [31] ......"

2) While barcodes embedded into the part are non-removable and not visible unless one inspects it with proper equipment, it is easy to detect for very stubborn malicious agent. When it is detected, what stops that malicious agent from fabricating parts with embedded barcode (counting availability of multi-material SLM machine)? The goal of embedding provenance is not only inability to remove but also inability to replicate the signature. Presented approach does not offer the latter.

As the composition of the tagging materials can be engineered such that duplication is more difficult. Not only $x$-ray imaging is required, but also $x$-ray analysis of tagging material properties (such as composition and phases) is needed to know tagging material properties. In addition, currently there are no commercial machines that can be used to manufacture imbedded metallic tags with the high resolution as described in this work, which has been protected by 4 patents. Only licensed users can have the access this technology.

3) One of the major question when part is being infiltrated with secondary material as how it's presence affects mechanical integrity and part performance. Authors did not perform any experimentation to offer insight about part performance.

a) Material compatibility of 316L and copper alloy has be investigated and confirmed by previous research. Please refer to page 3 and page 4 of the revised paper:

"......Previous investigations on multiple metallic material additive manufacturing $[32,33]$ indicated that copper and related alloys can be metallurgically bonded well with Ti6Al4V 
titanium alloy and 316L stainless steel, and the components achieved good mechanical performances, as the liquid phase contact angle between copper element and iron/titanium element was very small that led to strong thermodynamic driving force for the copper element infiltration[34,35]. Hence, Copper alloys were widely applied as infiltration materials in the selective laser sintered green part, using copper alloy to fill the parts' internal voids and strengthening the final parts [36] ......".

b) Furthermore, our previous paper ' $3 \mathrm{D}$ printing of multiple metallic materials via modified selective laser melting' [CIRP, Volume 67, Issue 1, 2018, Pages 245-248 ] provided a detailed analysis of interfaces between $316 \mathrm{~L}$ steel and the Cu10Sn alloy. This is referred to in this paper.

4) It is not clear how this solution will be implemented in the field for quick part authentication. Detection of signature via hand-held device would be beneficial to demonstrate.

a) A hand-held thermal imaging camera (FLIR Systems, T650sc) was used to capture the IR images in this investigation, as shown below.

b) A hand-held X-ray fluorescence (XRF) analyzer (Thermo Scientific, Niton XL3t-700s) was applied to examine the chemical components in this investigation, as shown below.

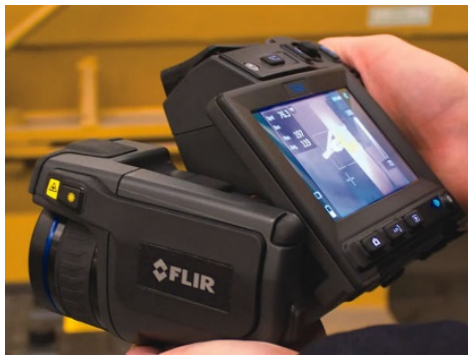

thermal imaging camera (FLIR Systems, T650sc)

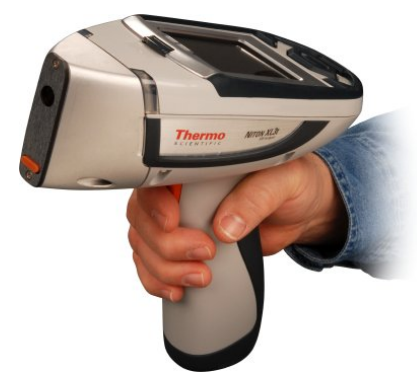

X-ray fluorescence (XRF) analyzer (Thermo Scientific, Niton XL3t-700s)

c) As for X-ray imaging, due to the power limitation of the hand-held X-ray machine and strong absorption to radiation photons by heavy metal elements used in this investigation, we did not find a suitable hand-held X-ray machine to do X-ray imaging in the market.

Please refer to page 21 of the revised paper:

"...... One of the challenges affecting the application of the present technology is how to quickly authenticate the part. As the heavy metal elements in stainless steel have stronger absorption to radiation photons, compared with non-metal and light alloy material, e.g. AlSi10Mg, while the working power of the normal hand-held X-Ray radiation detecting devices is limited to low level due to safety issues. Therefore, the embedding security material for components having a high material density should be further investigated to reduce the requirement on detector radiation intensity to achieve a sufficient feature recognition resolution. ......" 


\section{5) Some of figures mislabeled}

The mistakes of the figures labelling started from the Fig 11 in the initial manuscript. This has now been corrected.

All labels under the images and cited in the main body of the paper have been corrected.

6) Read proof

Proof reading was practiced again by a third person. 


\title{
Embedding Anti-counterfeiting Features in Metallic Components via Multiple Material Additive Manufacturing
}

\author{
Chao Wei, Zhe Sun, Yihe Huang, Lin Li* \\ Laser Processing Research Centre, School of Mechanical, Aerospace and Civil \\ Engineering, The University of Manchester, Oxford Road, Manchester, M13 9PL, UK \\ *email: lin.li@manchester.ac.uk
}

Declarations of interest: none

\begin{abstract}
The aerospace, automotive and medical industries are suffering from significant number of counterfeited metallic products that not only have caused financial losses but also endanger lives. The rapid development of additive manufacturing technologies makes such a situation even worse. In this investigation, we successfully applied a novel hybrid powder delivery selective laser melting (SLM) approach to embed dissimilar tagging material (Cu10Sn copper alloy) safety features (e.g. QR code) into metallic components made of 316L stainless steel. X-ray imaging was found to be a suitable method for the identification of the embedded safety features up to $15 \mathrm{~mm}$ in depth. X-ray fluorescence was used for the chemical composition identification of the imbedded security tagging material. A criterion for the selection of tagging material, its dimensions and imbedding depth is proposed. The multiple material SLM technology was shown to offer the potential to be integrated into metallic component production for embedding anti-counterfeiting features.
\end{abstract}

Keywords: Anti-counterfeiting, additive manufacturing, embedded security features, multiple-material, selective laser melting, QR code, non-destructive inspection

\section{Introduction}

Additive manufacturing (AM), adding materials layer by layer based on sliced 3D digital models to create 3D components and products [1], has the inherent flexibility and advantages of producing complex functional parts compared with conventional manufacturing approaches [2]. The rapid growth of the additive manufacturing technology in industry predicts a potential global market value of $\$ 21$ billion per year by 2020 [3], 48.4\% of which will be accounted for the highvalued added manufacturing applications in the aerospace, automotive, and 
medical industries [4]. Many applications in the above fields are related to functional and safety-critical parts, such as turbine blades in jet engines, and bone reinforcing medical implants. Any defects will not only damage the associated machines/devices, but also pose threads to the human lives. Unfortunately, all these 3 industries have been suffering from the illegal counterfeits. US Federal Aviation Administration (FAA) database reported more than 20 cases of aircraft crash between 2010 and 2017 due to fake components. The US National Transportation Safety Board (NTSB) reported 135 cases of unqualified aviation components found in the airplanes between 2011 and 2016 . Counterfeiting in the automotive industry is even worse, because counterfeiters can take the advantage of large batch of vehicle parts, hard to be physically distinguished from the original parts [5]. The World Customs Organization in Interpol estimated the global counterfeit vehicle spare parts market value was $\$$ 12 billion per year [6] and the U.S. automotive parts industry has lost $\$ 3$ billion in sales due to counterfeit goods [7].

The rapid adoption of AM technology makes the suppression of the counterfeit prevalence more difficult. The counterfeiters can copy generic products easily and quickly as long as they have the suitable 3D printers and 3D models that could be downloaded online or acquired through reverse engineering. General Electric (GE) filed a patent on a database platform based on the block-chain technology, an append-only transaction ledger [8], against the threat from 3D printed fake components [9]. European Union Intellectual Property Office (EUIPO) is also aware of this threat caused by new technical development [10].

Some researchers developed embedded security defective design features into the 3D CAD files in the design step [11,12], or embedding special fluorescent or visible light security features into the 3D printed polymer components [13-15]. Gupta et al carried out an investigation on embedding tracking codes, i.e. Quick Response (QR) code having fast readability and greater storage capacity [16], in additive manufactured parts for product authentication [17-19], and applied a micro-CT scanner to detect the embedded QR code in polymer components comprised of black and white resins, and laser sintered single metal component made of AlSi10Mg alloy, in which the powder particle in the QR code region were not fused and was left as lose powders [18]. This, however, may cause component fatigue failure due to the voids created. The technical limitations of existing commercial metal additive manufacturing technologies, including powder-bed fusion and directed energy deposition would make embedding security features of a high resolution difficult. Firstly, present commercial powder-bed fusion machine, e.g. selective laser melting (SLM) systems can only spread a single material on the same powder layer. If such a machine is used to embed the QR codes, the pixels of the QR code have to be designed as a set of voids filled with loose powder inside the solid components or a group of blind holes on the internal surface of the hollow components. Stress concentration will distribute around these small QR pixels, i.e. voids, and they can easily lead to the 
3D printed component fracture under high static/dynamic loading or fatigue failure due to cyclical stress after long working period [20-22]. It is notable that the density requirement of the 3D printed metal component used in the aerospace industry is close to $100 \%$. Undesirable voids are strictly prohibited. On the other hand, multiple material metal additive manufacturing would provide an alternative solution, as dissimilar metal material having a good metallurgical bonding with the main part material can be used as a tagging material and fill the pixel voids of QR code and firmly bonded with the main building material of the component after melting. The commercial directed energy deposition systems are available for multiple material metal depositions. InfraTrac company applied such multiple material system, i.e. Laser Metal Deposition (LMD), to embed a special tag into a titanium alloy part and detected it successfully with X-ray fluorescent equipment [23]. Due to the poor processing resolution of the LMD method, e.g. at sub-millimeter scale along the horizontal direction [24], it is not suitable for printing the tiny pixels in the QR code. More seriously, due to the use of gas delivery of the powders in the LMD processes, some powder particles can splash to other parts leading to the contamination of the building material and the tagging material [25].

Therefore it is important to develop a high resolution multiple metallic material additive manufacturing technology to embed tracking codes as a new anticounterfeiting approach. The embedded safety features should be easily and effectively identified by ordinary non-destructive testing approaches widely applied in industry, for instance, thermography, radiography, and fluorescent methods [26,27], and survive in the harsh working environment [28]. The resolution of SLM is typically 20-50 $\mu \mathrm{m}$ [29], much higher than that of directed energy deposition approaches [30]. This makes multiple material SLM a promising method to imbed tiny $\mathrm{QR}$ codes into the metallic components manufactured fully or partially with additive manufacturing. The University of Manchester demonstrated a novel ultrasonic selective powder delivery system integrated into powder bed SLM [31], which showed the potential for applications for the tailoring of local material prosperities in a component (e.g. medical implants), printing of mechanical-electronic integrated components (e.g. electric motors and batteries), and jewelries made of several types of precious metals. Here we applied this novel technology to a new anticounterfeiting application that enabled security features such as a QR code to be imbedded in metallic components at the users' choice. Infrared thermal imaging, X-ray imaging, and X-ray fluorescent methods were employed to identify the tag features. Microstructural and compositional analyses of the material interface were also carried out.

\section{Experimental materials and procedure}

\subsection{Materials}

Previous investigations on multiple metallic material additive manufacturing 
$[32,33]$ indicated that copper and related alloys can be metallurgically bonded well with Ti6Al4V titanium alloy and 316L stainless steel, and the components achieved good mechanical performances, as the liquid phase contact angle between copper element and iron/titanium element was very small that led to strong thermodynamic driving force for the copper element infiltration[34,35]. Hence, copper alloys were widely applied as infiltration materials in the selective laser sintered green parts, using a copper alloy to fill the parts' internal voids strengthening the final parts [36].

The main building material involved in this investigation was spherical 316L stainless steel powder of 10-45 $\mu \mathrm{m}$ diameters (Fig. 1a), supplied by LPW Technology Ltd., UK. Cu10Sn powder of 10-45 $\mu \mathrm{m}$ powder diameters (Makin Metal Powders Ltd. UK, Fig. 1b) was employed as the security tagging material The thermal properties and density of Cu10Sn and 316L are distinct [37], so they would be expected to present significant different infrared spectroscopic, X-ray fluorescent and X-ray image characteristics. As $\mathrm{Cu}$ and $\mathrm{Sn}$ elements are not present in the 316L chemical components (Table 1), the embedded features should be more easily observed by x-ray fluorescent analysis. The base plate was made of 304 stainless steel (120 mm diameter, $15 \mathrm{~mm}$ thickness).
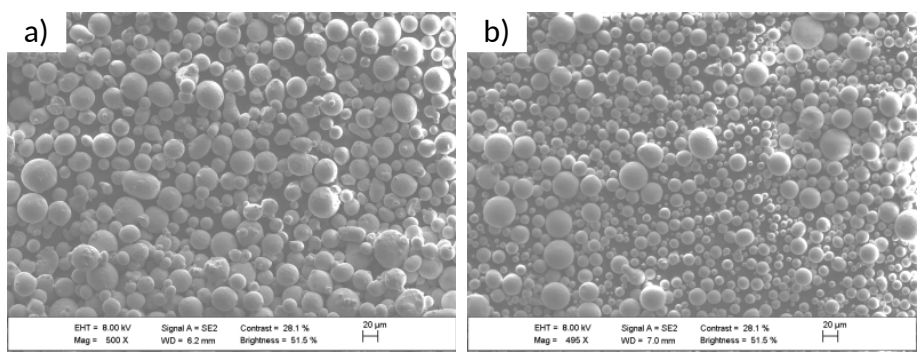

Fig. 1. SEM images of the powder materials used in this investigation a) 316L powder, b) Cu10Sn powder

Table 1: Chemical compositions of powders and the substrate used in this investigation [38]

\begin{tabular}{cccccccccccc}
\hline \multirow{2}{*}{ Material } & \multicolumn{10}{c}{ Chemical compositions (\%) } \\
\cline { 2 - 11 } & $\mathrm{Ni}$ & $\mathrm{Fe}$ & $\mathrm{Cr}$ & $\mathrm{Cu}$ & $\mathrm{Mo}$ & $\mathrm{Si}$ & $\mathrm{C}$ & $\mathrm{P}$ & $\mathrm{S}$ & $\mathrm{Sn}$ \\
\hline 316L & 10.5 & 69.85 & 16.6 & - & 2.2 & 0. & 0.03 & 0.02 & 0.01 & - \\
& & & & & & & 8 & & & & \\
Cu10Sn & 0 & 0 & - & Bal. & - & - & - & $0.10-0.35$ & - & $9.2-11.0$ \\
304 & 2.0 & $66.345-74$ & $18-20$ & - & - & 1. & 0.08 & 0.045 & 0.030 & - \\
\hline
\end{tabular}

\subsection{Experiment setup}

Experiments were carried out with a proprietary multiple material SLM system as shown in Fig. 2, designed at The University of Manchester. The focused laser beam ( $80 \mu \mathrm{m}$ spot size) from a $1070 \mathrm{~nm}$ continuous wave (CW) Ytterbium fiber laser source (IPG Photonics, YLR-500-WC) was used to selectively fuse thin layers of powders on the substrate. The main building material i.e. 316L powder 
was spread by a blade, and the tagging material, i.e. Cu10Sn was selectively deposited with a ultrasonic dispenser to desigated areas where one layer of 316L powder was selectively removed with a proprietary micro-vacuum system. A selective, single layer powder vacuum remover was implemented to remove lose powders selectively. The ultrasonic dry powder dispenser and the micro-vacuum powder selective remover were driven by an $x-y$ gantry stage. The oxygen content in the processing enclosure was controlled to be lower than $0.3 \%$ during the whole process by a vacuum pump and filling in the process chamber with argon gas.

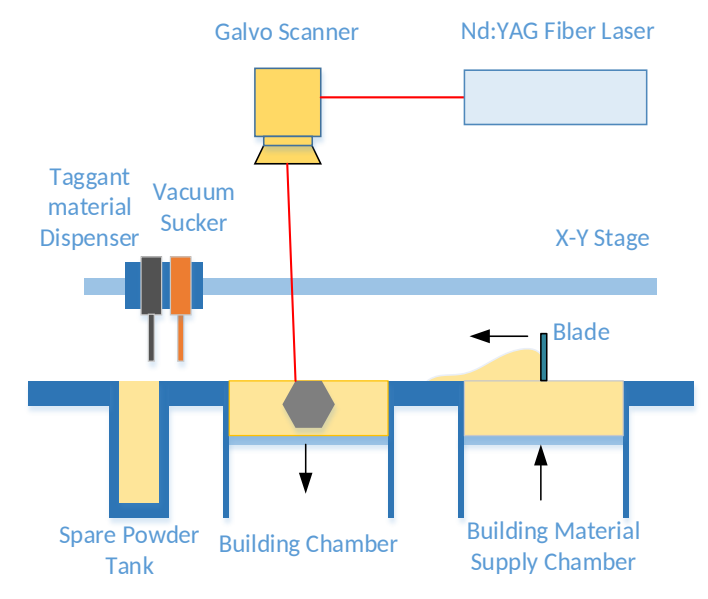

Fig. 2. Schematic diagram of the experimental setup.

\subsection{Component printing process}

The multiple material SLM process procedure was demonstrated in the previous work [31]. As presented in Fig. 3, a thin layer of the main building material i.e. 316L was firstly spread by a blade and subsequently the powder in the designed region was fused selectively with the laser beam. Then the unmolten powder at the defined QR-code position was removed for one layer by a micro vacuum cleaner to create a flat cavity of a specific pattern. The tagging material, i.e. Cu10Sn, was deposited into such a cavity of QR code pattern, and melted by the laser beam. To avoid powder material contamination to the building material, the laser melted QR code region was cleaned again with the micro vacuum system. Then, the building platform dropped down a given distance of single layer. These steps were repeated until the 3D component was created. A CCD vision system recorded the 3D printing process. Fig. 4 illustrates the recorded events as a component with imbedded security features was built. The laser process parameters are given in Table 2 . 


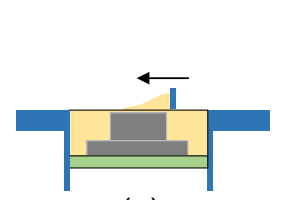

(a)

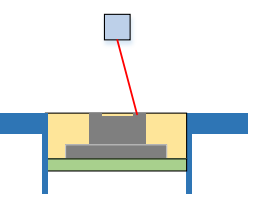

(b)

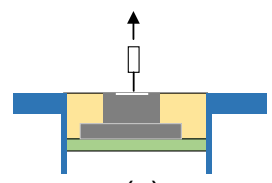

(c)

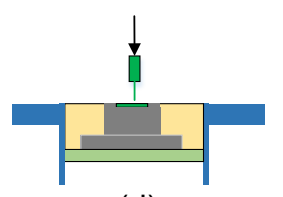

(d)

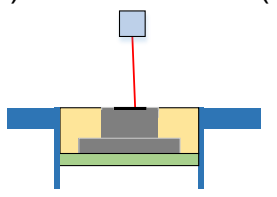

(e)

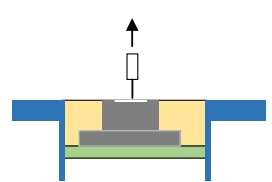

(f)

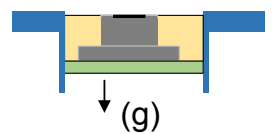

(g)

Fig. 3. An illustration of the multiple material SLM process flow for embedding safety features in metal parts
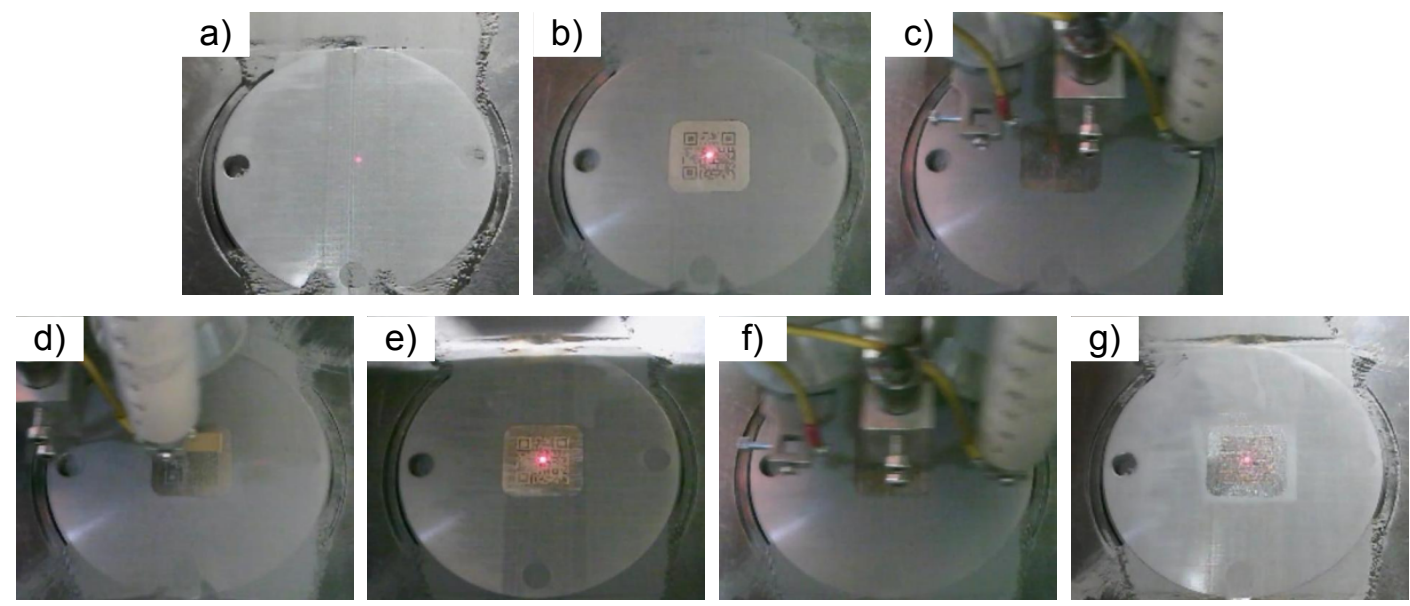

Fig. 4. The Recorded CCD images of embedded QR-code printing process, a) to g) are each step illustrated in Fig.3

Table 2: Multiple material SLM laser processing parameters

\begin{tabular}{rccccc}
\hline Material & $\begin{array}{c}\text { Laser power } \\
(\mathrm{W})\end{array}$ & $\begin{array}{c}\text { Scan speed } \\
(\mathrm{mm} / \mathrm{s})\end{array}$ & $\begin{array}{c}\text { Hatch distance } \\
(\mu \mathrm{m})\end{array}$ & $\begin{array}{c}\text { Relative } \\
\text { hatch angle } \\
\left({ }^{\circ}\right)\end{array}$ & $\begin{array}{c}\text { Layer thickness } \\
(\mu \mathrm{m})\end{array}$ \\
\hline 316L & 170 & 800 & 45 & 67 & 50 \\
Cu10Sn & 125 & 150 & 140 & 67 & 50 \\
\hline
\end{tabular}

\subsection{Sample Preparation}

\section{a) $Q R$ code samples}

A special QR code was designed as shown in Fig. 5a, where the QR codes (red color) and surrounding components (blue color) were made of Cu10Sn and 316L respectively. The information it represented was 'LPRC, University of Manchester'. Three additive manufactured samples with the QR code were produced. QR codes in these samples were built on the $15 \mathrm{~mm}$ thickness substrate directly. The code in sample A (Fig. 5a) was fully exposed outside on the top surface. Two-third of area of the code on sample B was covered by $316 \mathrm{~L}$ layers of a $1 \mathrm{~mm}$ thickness (see Fig. 5b). The entire embedded QR code on sample C (see Fig. 5c) was covered by 316 layers of a $2 \mathrm{~mm}$ in thickness. The QR 
code thickness was $0.5 \mathrm{~mm}$ in all three samples.

\section{b) Tagging ring samples}

Washers made of Cu10Sn material with different thickness were used as the tagging rings and attached to 304 stainless steel substrates (see Fig. 5d) to investigate the relationship between the tagging feature thickness and embedding depth for their $x$-ray identification. The tagging ring thicknesses were $0.2,1.0,1.5$, and $2.0 \mathrm{~mm}$, and their inner and outer diameters were $6.0 \mathrm{~mm}$ and $10.0 \mathrm{~mm}$ respectively, and the substrate thicknesses included 1.5 and $15.0 \mathrm{~mm}$. The X-ray was shot from the bottom of the substrate for this part of the experiment.

a)

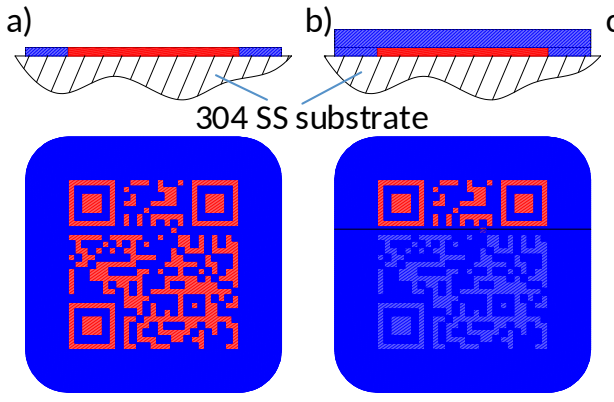

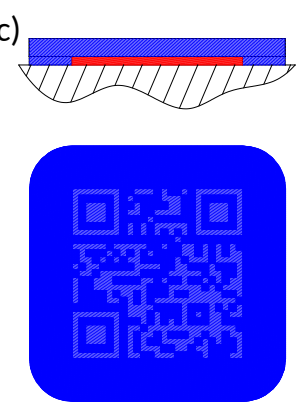

d)

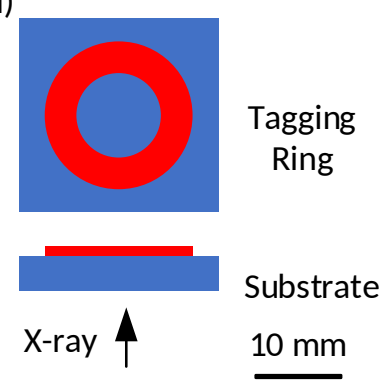

Fig. 5. a) to c) presents schematic diagram of the QR code sample A, B, C respectively, d) is the schematic diagram of the tag rings adhered on the 304 SS substrate where the X-ray shoot from the bottom of the substrate.

\subsection{Material characterization}

Infrared spectral images of the samples A and B were captured by a thermal imaging camera (FLIR Systems, T650sc). Before the thermal imaging, samples A and $B$ were heated up in a vacuum drying oven for 10 minutes and 60 minutes respectively. The vacuum drying oven chamber temperature and vacuum degree were kept at $120{ }^{\circ} \mathrm{C}$ and $0.01 \mathrm{~Pa}$ respectively.

$\mathrm{X}$-ray images of samples $\mathrm{A}$ and $\mathrm{C}$ were acquired with both $\mathrm{X}$-ray radiographic films and digital radiography comprising of a digital imaging receptor (Varian medical systems, PaxScan 2530) and a micro-focus X-ray tube (X-RAY WorX $\mathrm{GmbH}, \mathrm{XWT}-225-\mathrm{RAC})$. Due to the X-ray penetration depth limitation of the X-ray tube, holes were machined on the substrate bottom of samples $A$ and $C$ after the X-ray film imaging and before the digital X-ray examination, and the final substrate thickness was $1.5 \mathrm{~mm}$ below the SLM printed samples. Eight tagging ring samples were examined by the X-ray radiographic films. In all the inspections, the X-ray imaging exposure time, X-ray tube voltage and current were adjusted to the optimum values to achieve the best imaging resolution, and remained unchanged for the same substrate thickness.

X-ray fluorescence (XRF) analyzer (Thermo Scientific, Niton XL3t-700s) was 
applied to examining the chemical components of samples A and C.

After all the non-invasive inspections were completed, sample $\mathrm{C}$ was sliced and its metallographic cross-sections were prepared by cutting, mounting, grinding with $400 \#, 800 \#, 1000 \#$, and 1200\# grit emery papers, and polishing with 1.0 $\mu \mathrm{m}$ diamond polishing paste. Microstructure and material composition distribution at the material interfaces were acquired with scanning electron microscopy (Thermo Scientific, Quanta 450) equipped with energy dispersive spectroscopy (Oxford Instruments X-Max50).

\section{Results and discussion}

\subsection{Material Interface Microstructures of the $Q R$ code}

Fig. 6a shows an SEM image of the 316L/Cu10Sn interface at the joint zone of the Cu10Sn QR code and 316L top layers. A sound metallurgical bonding was revealed. No apparent defects were present in the fused $316 \mathrm{~L}$ and Cu10Sn regions. However, some micro-pores were observed in the area close to the joint line as indicated in the red frame in Fig. 6a. The porosity distribution is presented in Fig. 6b, converted from Fig. 6a with Image J software, where the porosity percentage was found to be around $0.33 \%$ (mean pore size was 0.56 $\mu \mathrm{m})$. The SLM processed components surface roughness was relatively poorer than that produced by traditional machining processes [39] and the ultrasonic deposited powder surface was uneven along the deposition tracks [40]. The above 2 factors lead to the increased roughness of the fused Cu10Sn surface. Porosity is known to be sensitive to the powder deposition quality [41]. As a result, pores mostly occurred in the material joint interfaces.

The EDS inspection (Fig. $6 \mathrm{~b}$ to Fig. 6e) showed the chemical elements distribution. The result indicated that the build material i.e. 316L and tagging material i.e. Cu10Sn were deposited at the specified region. No material contamination or infiltration beyond the interfacing areas was observed. 


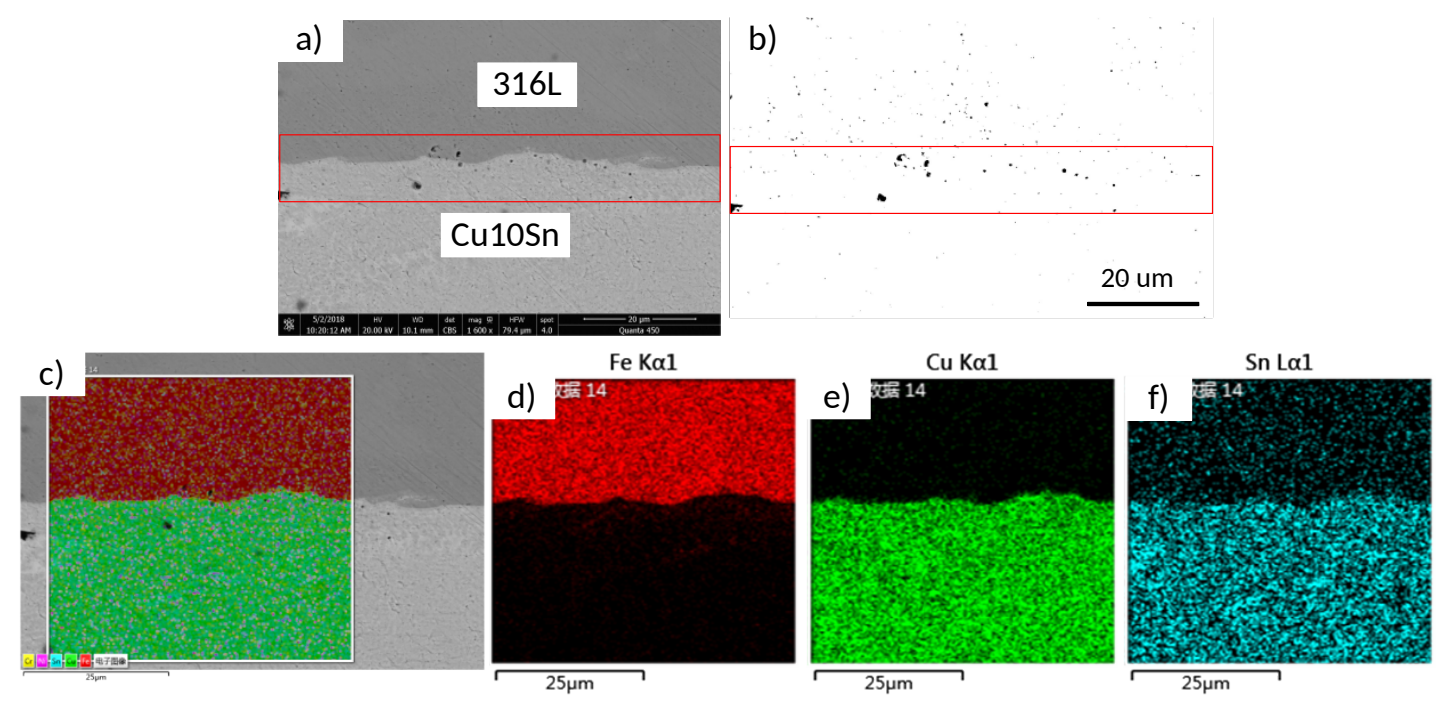

Fig. 6. SEM and EDS elemental distributions of the 316L-Cu10Sn interface a) The SEM image of the 316L-Cu10Sn material interface of sample $\mathrm{C}, \mathrm{b}$ ) the porosity distribution converted from a), c) the EDS mapping of the 316-Cu10Sn interface, d) to f) the Fe, Cu, Sn element distribution at the 316L-Cu10Sn interface.

\subsection{Infrared thermal imaging of the $Q R$ codes}

\subsubsection{Finite Element Analysis of Heat Distributions}

Finite Element Method (FEM) was applied to understand the temperature evolution of QR code samples during the heating-up/cooling-down processes before the infrared thermal imaging. The heat transfer in the vacuum drying oven cabinet was comprised of conduction, convection and radiation [42,43]. In this study, convection was neglected as the heating process was in a vacuum environment.

Thermal properties of tagging QR code material and surrounding main body component metal were temperature dependent $[44,45]$. The temperaturedependent thermal properties of Cu10Sn and 316L are listed in Table 3 and Table 4 respectively.

Table 3: Thermal conductivity and specific heat of Cu10Sn copper alloy [45]

\begin{tabular}{ccc}
\hline Temperature $\left({ }^{\circ} \mathrm{C}\right)$ & Thermal conductivity $\left(\mathrm{W} / \mathrm{m}^{\circ} \mathrm{C}\right)$ & Specific heat $\left(\mathrm{J} / \mathrm{kg}^{\circ} \mathrm{C}\right)$ \\
\hline 20 & 400.68 & 383.48 \\
27 & 401.00 & 385.00 \\
77 & 396.78 & 392.00 \\
100 & 395.20 & 394.73 \\
127 & 393.00 & 398.44 \\
\hline
\end{tabular}

Table 4: Thermal conductivity and specific heat of Stainless Steel 316L [44] 


\begin{tabular}{ccc}
\hline Temperature $\left({ }^{\circ} \mathrm{C}\right)$ & Thermal conductivity $(\mathrm{kW} / \mathrm{m})$ & Specific heat $\left(\mathrm{J} / \mathrm{kg}^{\circ} \mathrm{C}\right)$ \\
\hline 0 & 13.286 & 456.7831 \\
20 & 43.635 & 464.7276 \\
50 & 14.151 & 475.7837 \\
100 & 14.992 & 492.0655 \\
150 & 15.813 & 505.9089 \\
\hline
\end{tabular}

The sample surface was heated based on radiation heat transfer. The heat transfer between QR code, 316L part, and the substrate was through conduction. The radiation coefficients of the build metal (316L) and the QR code (Cu10Sn) were set as 0.85 and 0.75 respectively [46]. In the heating-up process, the initial sample temperature was $15^{\circ} \mathrm{C}$ and the temperature in the furnace was set at $120{ }^{\circ} \mathrm{C}$. Stefan-Boltzmann constant is $5.67 \times 10^{-8} \mathrm{~J} /\left(\mathrm{m}^{2} \cdot \mathrm{K}\right)$. In the cooling-down process, the sample was cooled in normal room environment, so the ambient temperature was $15{ }^{\circ} \mathrm{C}$, and the conductive coefficients of QR code and base metal were set as $46 \mathrm{~W} /(\mathrm{m} . \mathrm{K})$ and $16.3 \mathrm{~W} /(\mathrm{m}$. K) [47] respectively. The rest of thermal boundary conditions were kept the same as in the heating-up process.

In the heating-up process, the governing equations of conductive and radiative heat transfers are presented in equations (1) and (2) respectively [48]. In the cooling-down process, samples were cooled by convection and radiation heat transfer. The equation of convective heat transfer can be illustrated by formula (3). The 3D models for simulation were the same as the printed samples, comprised of the Cu10Sn QR code, the 316L part and the 304 stainless steel substrate. The FEM modelling and analysis were implemented on the commercial software ABAQUS.

$$
\rho C_{p} \frac{\partial T}{\partial t}=-\nabla \cdot(-k \nabla T)
$$

where $\rho$ is the density, $T$ is the temperature, $C_{p}$ is the specific heat.

$$
q=\varepsilon \sigma\left(T^{4}-T_{r}^{4}\right)
$$

where $\varepsilon$ is the emissivity, $\sigma$ is the Stefan-Boltzmann constant and $T_{r}$ is the ambient temperature.

$$
Q_{c}=h_{c} A\left(T-T_{r}\right)
$$

Where $h_{c}$ is the convective coefficient and $A$ is the surface area subjected to convection heat transfer. 


\section{a) Heating-up process simulation result}

The exposed QR code and the partialy covered QR code temperature distributions as heating-up time increasing are presented in Fig. 7a and Fig. 7b respectively. For the exposed QR code on the surface, the 316L part showed a maximum temperature of $51^{\circ} \mathrm{C}$ while the Cu10Sn QR code was $35^{\circ} \mathrm{C}$ after heating up for $10 \mathrm{~min}$, hence a clear QR code could be identified. For other samples, we did not find significant temperature differences between the Cu10Sn QR code and the surrounding 316L until the samples were heated up for 1 hour, as indicated in Fig. $7 \mathrm{~b}$.

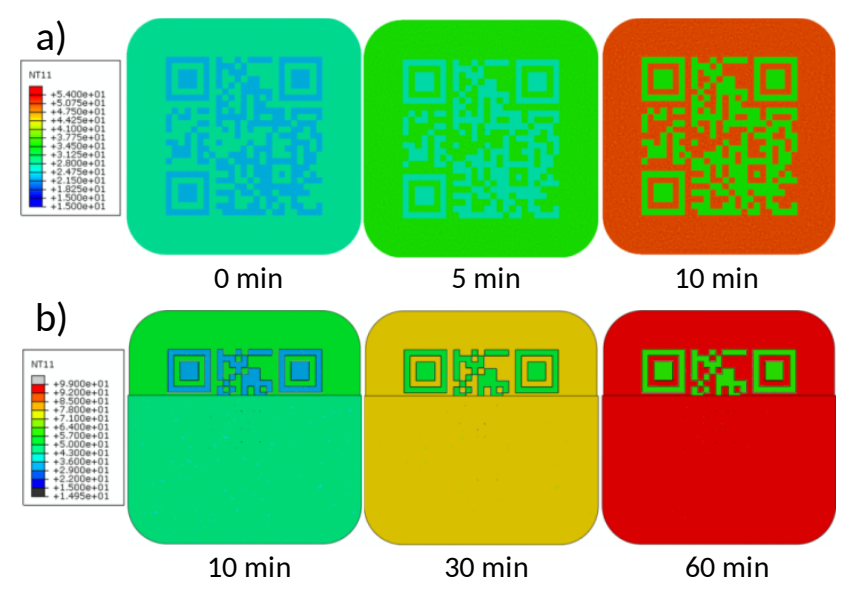

Fig. 7. a) and b) show the simulated temperature distribution of the exposed QR code as time increasing and that of the partly covered QR code respectively, using FEM modelling

The simulated temperature history of the above two samples in the heating up process is plotted in Fig. 8. It is notable that the 316L part temperature was always higher than that of the Cu10Sn part. The specific heat capacity of Cu10Sn $((380 \mathrm{~kJ} /(\mathrm{kg} \cdot \mathrm{K}))$ is lower than that of $316 \mathrm{~L}(500 \mathrm{~kJ} /(\mathrm{kg} \cdot \mathrm{K}))$ [47]), so that Cu10Sn per area should receive more energy during the heating-up procedure. However, as both the Cu10Sn part and 316L part were adhered on the substrate of a15 mm in thickness, and the thermal conductivity of Cu10Sn $(46 \mathrm{~W} /(\mathrm{m} . \mathrm{K})$ ) is 2.82 times of that of $316 \mathrm{~L}(16.3 \mathrm{~W} /(\mathrm{m} . \mathrm{K}))$ [47]). As a result, Cu10Sn transferred more energy to the surrounding material by thermal conduction, and its final temperature was lower than that of 316L part. 

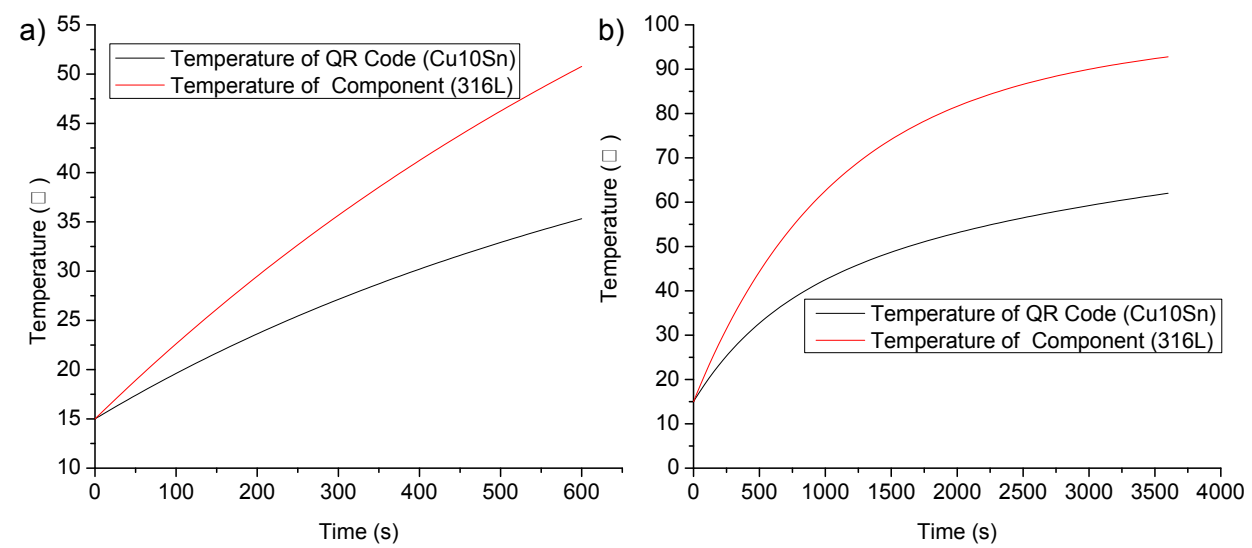

Fig. 8. Simulated temperature history of the QR code as heating-up time increasing, a) exposed QR code, b) Partly covered QR code.

\section{b) Cooling-down process simulation result}

Fig. 9a shows the temperature distribution of the exposed QR code during the cooling down process. Its image contrast was decreased as the temperature difference between Cu10Sn part and 316L part reduced with time. Fig. 9b presents the temperature distributions of the partly covered QR code at $20 \mathrm{~min}$ intervals. Temperature difference caused by the subsurface QR code was not identifiable.

a)
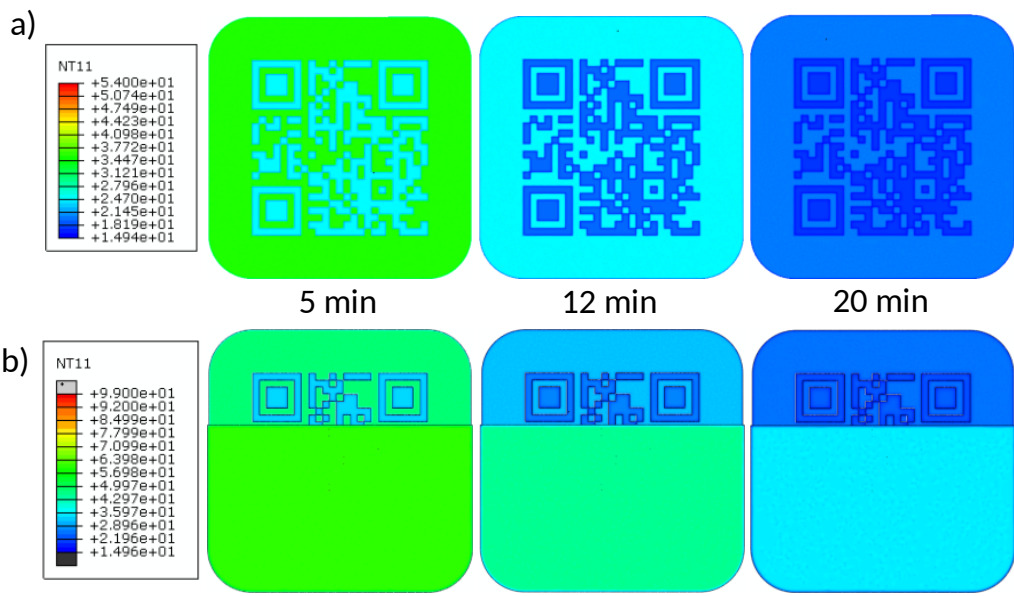

$12 \min$

$20 \min$

$20 \min$

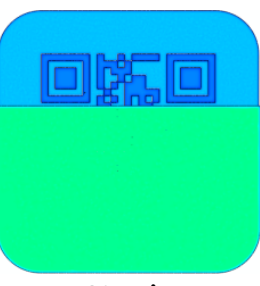

$40 \min$

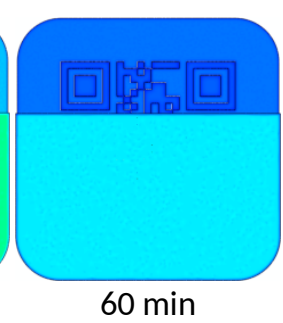

Fig. 9 The simulated temperature distribution of QR code samples as cooling-down time increasing, a) the exposed QR code, b) the partly covered QR code.

Fig. 10 shows the simulated temperature plots during cooling process. The difference between Cu10Sn and 316L reduced as time increased because of the heat dissipation. A steady state temperature was reached at a point close to the room temperature. The QR code was relatively cooler due to higher thermal conductivity. 

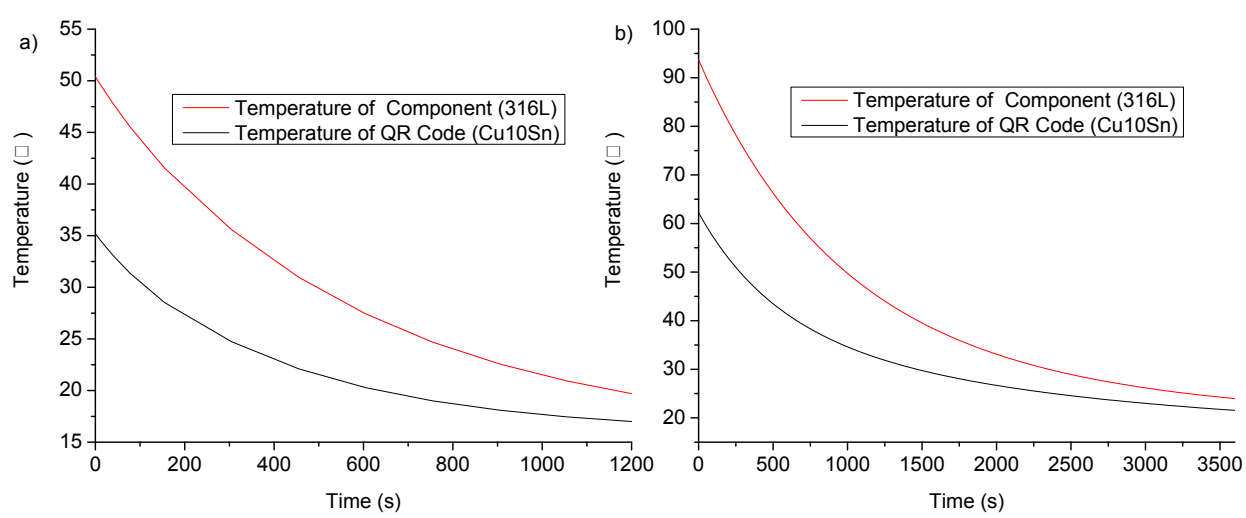

Fig. 10 Simulated temperature history of the QR code as cooling-down time increasing, a) exposed QR code, b) Partly covered QR code.

The FEM analysis indicated that: a) a clear QR-code pattern on the surface could be observed due to distinct material temperature distribution differences between the two materials, b) The $\mathrm{Cu}$ alloy $\mathrm{QR}$ was cooler than the surrounding 316L steel. c) no discernable temperature differences was found if Cu10Sn was covered by a 316L layer, both in the heating-up and the cooling-down processes.

\subsubsection{Infrared thermal imaging experimental result}

The thermal imaging mechanism for tagging identification was based on thermal radiation heat transfer rate difference between different materials. According to equation (4) [49], the net irradiative heat transfer, $\varnothing$, increases as the increase of the emissivity $\varepsilon$, of the target material, determined by the material thermal properties, surface roughness, and the environment temperature.

$$
\varnothing=\frac{E_{b}-J}{\frac{1-\varepsilon}{\varepsilon A}}
$$

Where $\varnothing$ is the net radiative hear transfer, $E_{b}$ is the black body radiation, $J$ is the effective surface reflection, $\varepsilon$ is emissivity ratio, $A$ is the surface area.

Due to the emissivity and thermal conductivity differences between Cu10Sn and 316L, the QR-code and the main body present obvious temperature differences as shown in Fig. 11c and Fig. 11d after heating up in a $120{ }^{\circ} \mathrm{C}$ oven and a clear QR code was identified. A higher temperature $\left(46.9{ }^{\circ} \mathrm{C}\right)$ was observed on the $316 \mathrm{~L}$ part, and a lower temperature $\left(33.8^{\circ} \mathrm{C}\right)$ was found on the QR code after heating for 10 min. By comparing Fig. 11b to Fig. 11d or Fig. $11 \mathrm{f}$ to Fig. $11 \mathrm{~h}$, the temperature difference between the Cu10Sn and 316L parts was enlarged with increasing heating-up time due to thermal energy accumulation. 

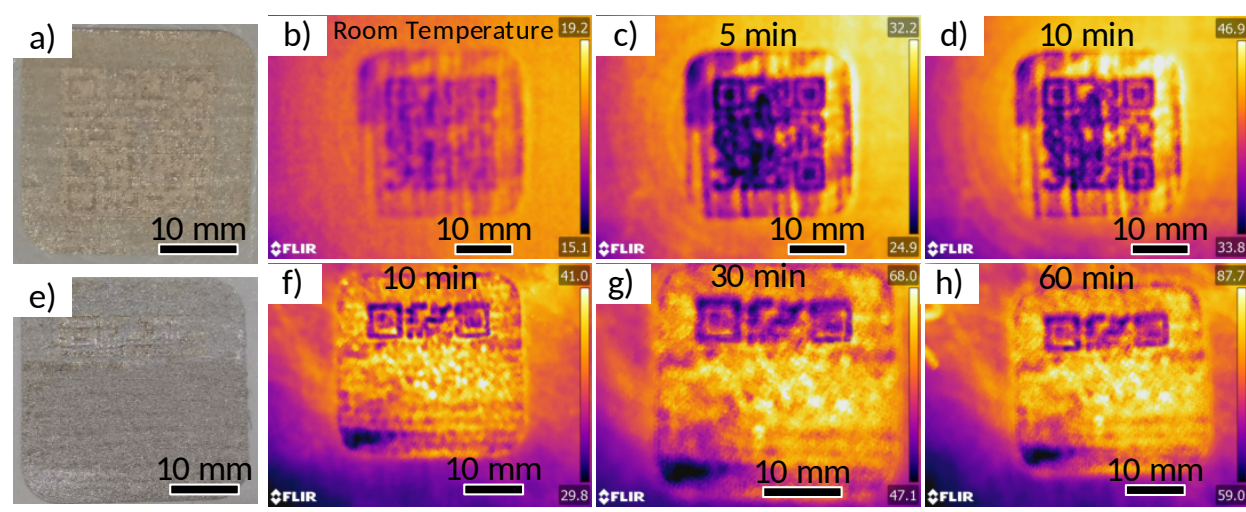

Fig. 11. Thermal imaging of surface and embedded QR codes, a) and e) optical images of the samples A and B respectively, b) to d) show the infrared thermal images of sample A after heating up in the $120{ }^{\circ} \mathrm{C}$ oven for $0 \mathrm{~min}, 5 \mathrm{~min}$, and $10 \mathrm{~min}$ respectively, f) to h) present the thermal infrared images of the sample B after heating up in the $120{ }^{\circ} \mathrm{C}$ oven for $10 \mathrm{~min}$, $30 \mathrm{~min}$, and $60 \mathrm{~min}$ respectively.

Fig. $11 \mathrm{f}$ to Fig. $11 \mathrm{~h}$ present the thermal images of sample B. It was notable that the thermal fields of the two thirds QR code area covered by the $1 \mathrm{~mm} \mathrm{316L}$ layer were almost the same as that of the rest of 316L part, regardless of the heating up duration. No temperature difference caused by the sub-surface Cu10Sn QR code was observed. This result agreed with the FEM analysis.

\section{3. $X$-ray imaging of the $Q R$ code}

\subsubsection{Theoretical derivation}

$\mathrm{X}$-ray is electromagnetic radiation with high energy. The radiation photons are absorbed or scattered by the matter in the beam path due to photoelectric and Compton effects. Hence the X-ray intensity will be attenuated after it penetrates into the matter [51]. The X-ray intensity $I(x)$ is dominated by the depth of barrier $x$, and the mass attenuation coefficient, $\mu$, according to the exponential attenuation law, commonly known as Beer-Lambert's law, described as [52].

$$
I(\mu, x)=I_{0} e^{-\mu x}
$$

Where $I_{0}$ is the incident intensity, $x$ is the barrier depth, $\mu$ is the mass attenuation coefficient.

In this investigation, the detected X-ray intensities at the typical component region and the tagging region were converted from equation (5), as illustrated in equation (6) and (7) respectively.

$$
I_{\text {comp }}=I_{0} e^{-\mu_{1} x_{1}} e^{-\mu_{1} x_{2}} e^{-\mu_{3} x_{3}}=I_{0} e^{-\left(\mu_{1} x_{1}+\mu_{1} x_{2}+\mu_{3} x_{3}\right)}
$$




$$
I_{\text {tag }}=I_{0} e^{-\mu_{1} x_{1}} e^{-\mu_{2} x_{2}} e^{-\mu_{3} x_{3}}=I_{0} e^{-\left(\mu_{1} x_{1}+\mu_{2} x_{2}+\mu_{3} x_{3}\right)}
$$

Where $\mu_{1}, \mu_{2}, \mu_{3}$ present the incident intensity of 316L, Cu10Sn and 304 respectively, and $x_{1}, x_{2}, x_{3}$ are the thickness of the cover layer, tag part and substrate respectively. All these symbols are illustrated in Fig. 12.

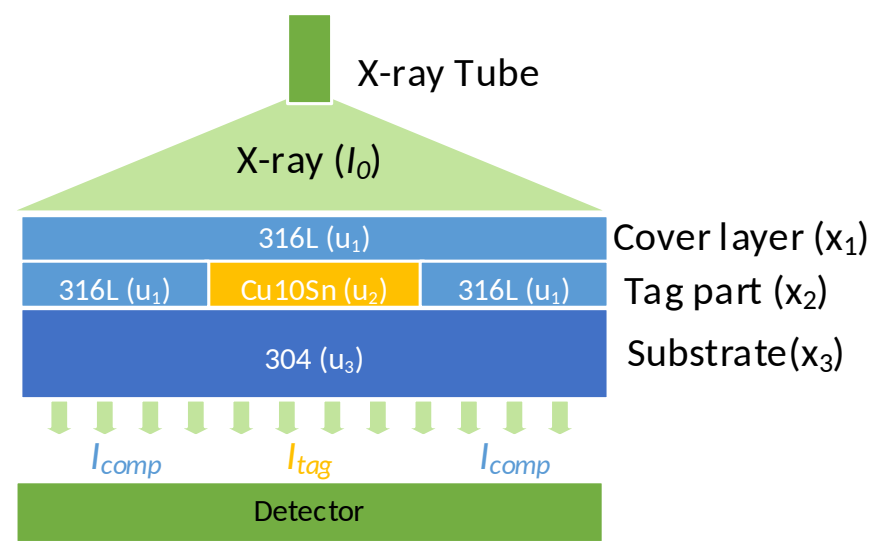

Fig. 12. The Schematic diagram of the X-ray penetrating the component with the tag

Increasing embedding depth, tag thickness and the substrate thickness would lead to an exponential reduction in the detected X-ray intensity and a significant imaging resolution drop. The total thickness of above three individual parts in the inspection region would affect the imaging resolution. Besides, increasing the incident intensity $I_{0}$ is helpful to improving the resolution.

The contrasts CONT (i.e. the imaging contrast) between the component area and the tag area are further described by the equation (8) [53].

$$
\text { CONT }=\ln \frac{I_{\text {comp }}}{I_{\text {tag }}}=\ln \frac{I_{0} e^{-\left(\mu_{1} x_{1}+\mu_{1} x_{2}+\mu_{3} x_{3}\right)}}{I_{0} e^{-\left(\mu_{1} x_{1}+\mu_{2} x_{2}+\mu_{3} x_{3}\right)}}=\left(\mu_{2}-\mu_{1}\right) x_{2}
$$

It shows that the imaging contrast is only related to the difference between the mass attenuation coefficient of component and that of tagging material, and the tag thickness. A higher material mass attenuation coefficient difference and a thicker tag would result in higher imaging contrast.

According to equations (9) and (10) which describe the mass attenuation coefficient of the mixture and that of a single element respectively [52,54], the chemical elements having a high density, i.e. high relative atomic mass and related mixture should have a relatively higher mass attenuation. Hence applying a high density material, for instance Cu10Sn, as the tagging material is a feasible 
approach to increase the X-ray imaging contrast.

$$
\begin{gathered}
\mu=\rho \sum_{i} \omega_{i}\left(\frac{\mu_{i}}{\rho_{i}}\right) \\
\mu_{i}=\sigma_{i} / u A_{i}
\end{gathered}
$$

Where,

$$
\begin{aligned}
& \mu-\quad \begin{array}{l}
\text { mass attenuation coefficient of the mixture } \\
\text { density of the mixture }
\end{array} \\
& \omega_{i}-\quad \begin{array}{l}
\text { proportion by weight of the } \mathrm{i}^{\text {th }} \text { element in a mixture } \\
\mu_{i}-\quad \text { mass attenuation coefficient of the } \mathrm{i}^{\text {th }} \text { element in a mixture }
\end{array} \\
& \rho_{i}-\quad \text { density of the } \mathrm{i}^{\text {th }} \text { element in a mixture } \\
& \sigma_{i}-\quad \text { the cross section per atom of the } \mathrm{i}^{\text {th }} \text { element in a mixture } \\
& u-\quad \text { the atomic mass unit }\left(1 / 12 \text { of the mass of an atom of the nuclide }{ }^{12} \mathrm{C}\right) \\
& A_{i}-\quad \text { the relative atomic mass of the } \mathrm{i}^{\text {th }} \text { element in a mixture }
\end{aligned}
$$

Therefore, the X-ray imaging resolution is expected to be affected by the total thickness of the X-ray inspected region containing the tagging feature under the determined material composition and X-ray incident intensity. It will be decreased exponentially as the depth of the cover material thickness increases. Secondly, choosing a heavier metal as the tagging material and increasing the tag thickness would be helpful for the enhancement of the X-ray imaging contrast.

\subsubsection{X-ray imaging Result}

The digital X-ray image (Fig. 13b) clearly identified the QR-code on the top surface of sample A. The lower the material density, i.e. atomic weight of the material is, the more transparent the material is to X-rays and the lighter its image will be [55]. The densities of the 316L and Cu10Sn are $8.00 \mathrm{~g} / \mathrm{cm}^{3}$ and $8.78 \mathrm{~g} / \mathrm{cm}^{3}$ respectively [38], hence the color of $316 \mathrm{~L}$ material was lighter than that of Cu10Sn as shown in Fig. 13b.

Fig. 13d shows the digital X-ray image of the sample $\mathrm{C}$, in which the QR-code was covered by the 316L layer of a $2 \mathrm{~mm}$ in thickness. The $316 \mathrm{~L}$ cover layer made the QR-Code darker than that in Fig. 13b, as X-ray absorption was affected by the thickness of the object [55].

To further investigate the influence of the embedding depth on the QR-code recognition, sample $A$ and $C$ were examined from both top and the bottom where 
the QR-Code's cover layer was $15.0 \mathrm{~mm}$. Because of the limitation of the penetration depth of the digital X-ray system, we had to employ the traditional radiographic film method, whose photon penetration depth was much higher, but the image resolution was poorer compared with the digital X-ray images. Clear QR-code outlines were still observed for both samples A and C from the bottom view as shown in Fig. 14c and Fig. 14f. The difference of the X-ray images between the top view and the bottom view (i.e. Fig. 14b and Fig. 14c, Fig. 14e and Fig. 14f) was that the samples with a $15 \mathrm{~mm}$ cover layer thickness showed poorer contrasts. However, these did not affect the QR-code imaging resolution.

The color contrast of Cu10Sn and 316L in Fig. 14b (where the thickness of the substrate before machining and that of the QR-Code was $15.0 \mathrm{~mm}$ and $0.5 \mathrm{~mm}$ respectively) was much lower than that in Fig. 13b (where the thickness of the substrate after machining and that of the QR-Code was $1.5 \mathrm{~mm}$ and $0.5 \mathrm{~mm}$ respectively). More x-ray signal was absorbed by the thick background, and the contribution of the thin QR-code was weakened. It means that the thickness of the embedded safety features should be proportional to the thickness of the components along the X-ray examination direction if one wishes to observe the embedded features with a clear contrast of the X-ray image, regardless of the safety features were on the top surface, sub-surface or deeply embedded in the main body.

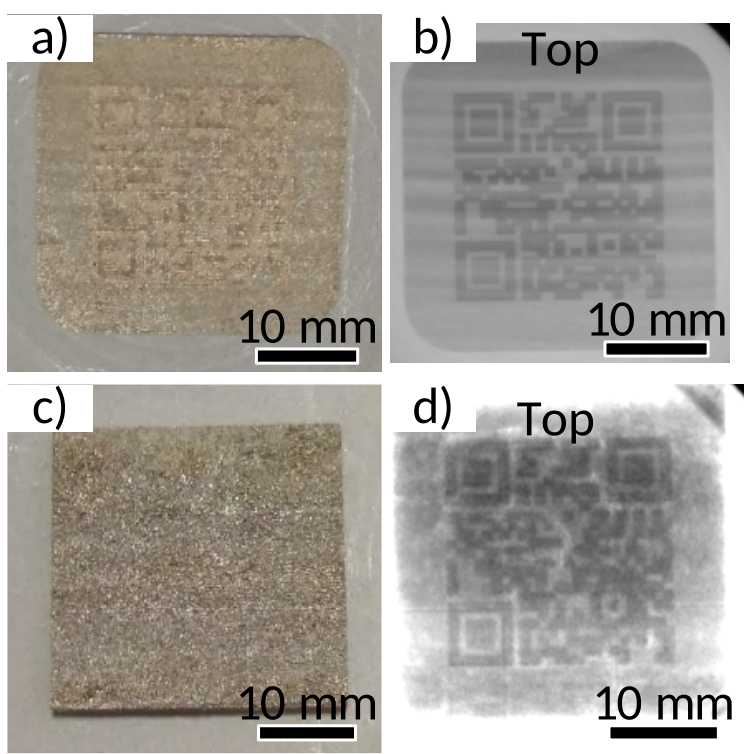

Fig. 13. a) and c) shows the optical images of the samples A and C, b) and d) show digital X-ray images of samples $A$ and $C$ from the top view. 

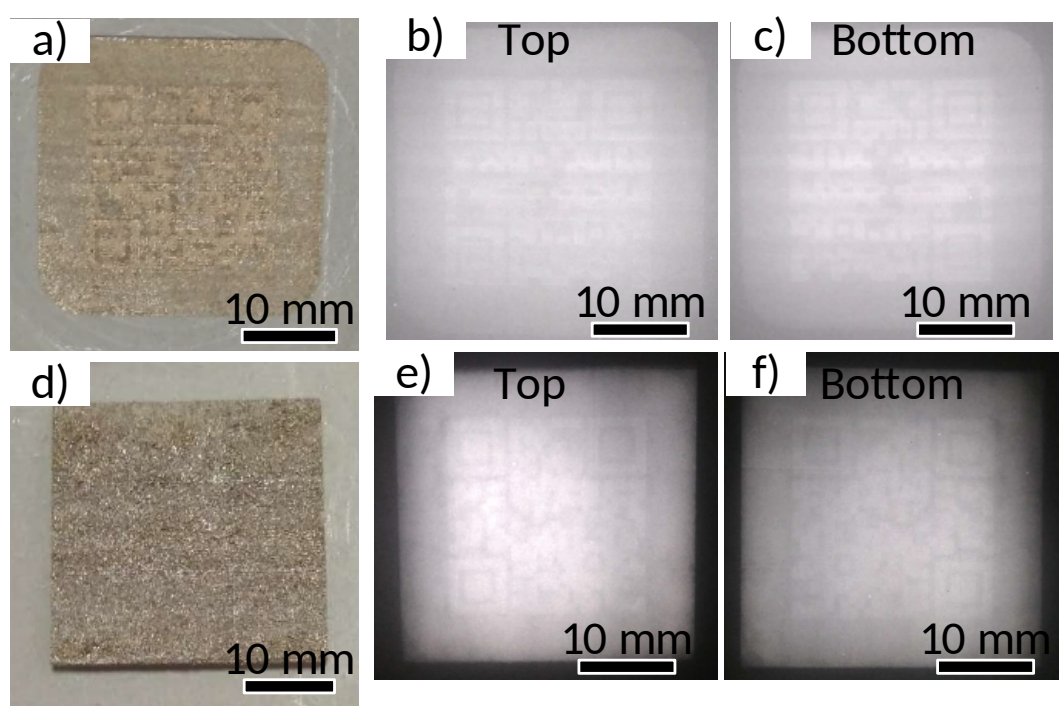

Fig. 14. a) and d) shows the optical images of the samples $A$ and $C, b$ ) and c) show the radiographic film images of sample A from the top view and bottom view respectively, e) and f) show the radiographic film images of sample $\mathrm{C}$ from the top view and bottom view respectively.

\subsection{X-ray imaging of the tagging rings}

To further examine the relationship between the embedding feature thickness and embedding depth, a set of tagging rings adhered on the 304 substrates were inspected by the X-ray from the bottom of the substrate and the imaging results are shown in Fig. 15a. The X-ray image was based on greyscale, made up of black and white grades [56]. ImageJ software was applied to measure the grey levels of each tagging ring X-ray image, presented in Fig. $15 \mathrm{~b}$ and Fig. 15c, along with the $\mathrm{X}$ axial-radial directions. The grey level indicates the brightness of pixels. The minimum grey level (black) is 0, the maximum value (white) is 255 [57].

As shown in Fig. 15b, the grey value of the tagging ring with a $0.2 \mathrm{~mm}$ thickness at its ring wall region was much lower than that of the rings with thickness at or greater than $1.0 \mathrm{~mm}$. A clear imaging contrast between the wall region made of Cu10Sn and the centre hole region where the $1.5 \mathrm{~mm}$ thickness substrate exposed was demonstrated. The grey values of Cu10Sn and 304 were 160 and 80 respectively.

While the curves of the samples with a substrate thickness of $15 \mathrm{~mm}$ (Fig. 15c) fluctuated much more significantly than that with a substrate thickness of 1.5 mm (Fig. 15b) due to the drop of the resolution caused by the X-ray intensity exponential attenuation indicated in in equation (5). The imaging contrast almost disappeared for the $0.2 \mathrm{~mm}$ tag as shown in the black curve in Fig. 15c. For thicker tags, the contrasts were still observable while their differences were reduced comparing with the results with the thinner 304 substrate. 
a)

\begin{tabular}{ccccc}
\hline Substrate & \multicolumn{5}{c}{ Tagging Ring Thickness $(\mathrm{mm})$} \\
\cline { 2 - 5 } Thickness $(\mathrm{mm})$ & 0.2 & 1.0 & 1.5 & 2.0 \\
\hline
\end{tabular}
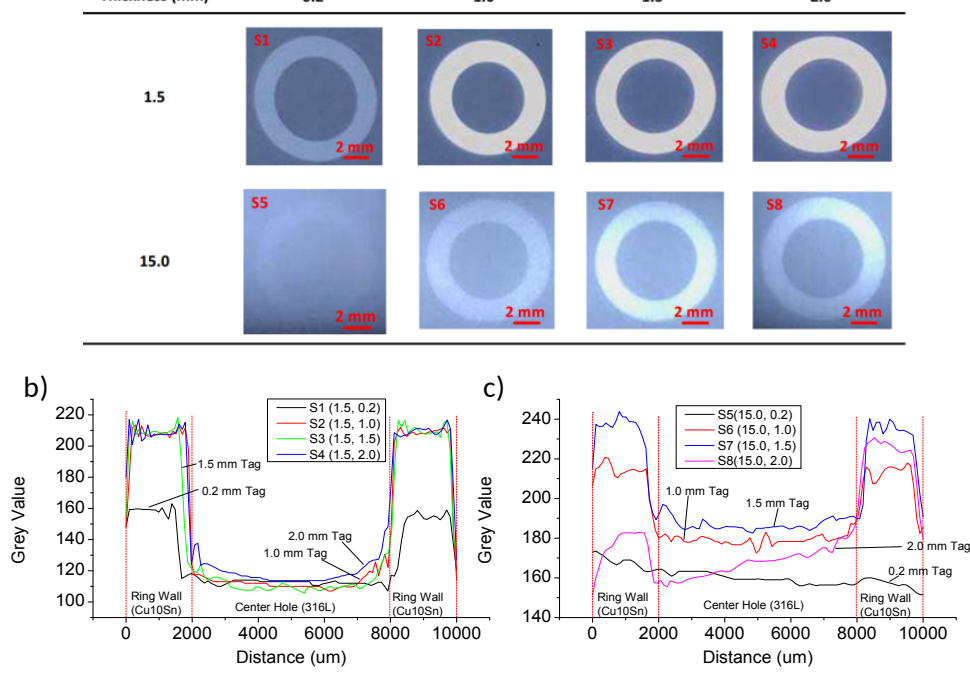

Fig. 15. a) The X-ray images of the tagging ring samples, b) and c) show grey value plot along the $X$ axial-radial direction of the tagging ring samples on the $1.5 \mathrm{~mm}$ and $15.0 \mathrm{~mm}$ substrate respectively.

From the above analysis, the imaging contrast of the X-ray identification was increased with the increase of the tagging feature thickness. The imaging resolution was decreased as the embedding depth increased. The deteriorative imaging resolution weakened the imaging resolution.

\subsection{X-ray fluorescence (XRF) of the $Q R$ codes}

As indicated in Table 1, the chemical composition of the tag material Cu10Sn is different from that of the building material 316L. The key elements in Cu10Sn are $\mathrm{Cu}$ and $\mathrm{Sn}$, and the ones comprising of the 316 $\mathrm{L}$ are $\mathrm{Fe}, \mathrm{Cr}$, and $\mathrm{Ni}$. The XRF was applied to analyse the chemical compositions of the QR-code area of the samples $\mathrm{A}$ and $\mathrm{C}$. The percentages of elements of these 5 key elements, including $\mathrm{Cu}, \mathrm{Sn}, \mathrm{Fe}, \mathrm{Cr}$, and $\mathrm{Ni}$, are shown in Fig. 16.

All chemical elements of Cu10Sn and 316L were detected on sample A, especially the strong $\mathrm{Cu}$ signal (67.67\% in Fig. 16) from the tag material $\mathrm{Cu} 10 \mathrm{Sn}$. The Sn signal on sample A (7.20\%) was 21 times stronger than that on sample C $(0.36 \%)$ where $\mathrm{Sn}$ was covered by stainless steel layers. All the key elements (i.e. $\mathrm{Cr}, \mathrm{Fe}$, and $\mathrm{Ni}$ ) of $316 \mathrm{~L}$ building material in sample A were much lower than those in the sample C $(7.05 \%$ / 17.53\%, 14.21\% / 61.05\%, and 2.24\% / 11.82\% respectively). Because the QR code made of Cu10Sn occupied the biggest area for the XRF examination, and the 316L material just filled the space around the pixels of the QR-code. Therefore the element radiation photons emitted by $316 \mathrm{~L}$ material was much less.

For sample C, where the QR-code was covered by a $2 \mathrm{~mm}$ thick 316L layer, the strongest chemical element signal was contributed by Fe (61.05\%) which is 
the main part of the 316L material. $\mathrm{Cu}$ and $\mathrm{Sn}$ elements were still observed ( $4.36 \%$ and $0.36 \%$ respectively), but were much weaker than that emitted by the exposed ones (67.67\% and $7.20 \%$ respectively) for sample A. This is because the chemical composition is identified by the intensity of the fluorescence signal at the detector, emitted from the object excited by the initial X-ray source [58]. Such a signal is affected by both the sample attenuation coefficient for the fluorescent energy, and the distance from the sample surface to the interaction point along the beam direction [59]. Hence the deeper the QR-code is embedded, the weaker its fluorescent signal will be. Besides, the fluorescent penetration depth for the heavy metal matrix was in several ten micrometers scale, and reaches the millimeter range for the light matrix [60]. It is essential to determine the suitable embedding depth and light chemical element as the tagging if XRF was chosen as the tool to identify the embedded anti-counterfeiting features. It also means that the XRF method is only suitable for detecting the tagging material on the surface or at the close sub-surface.

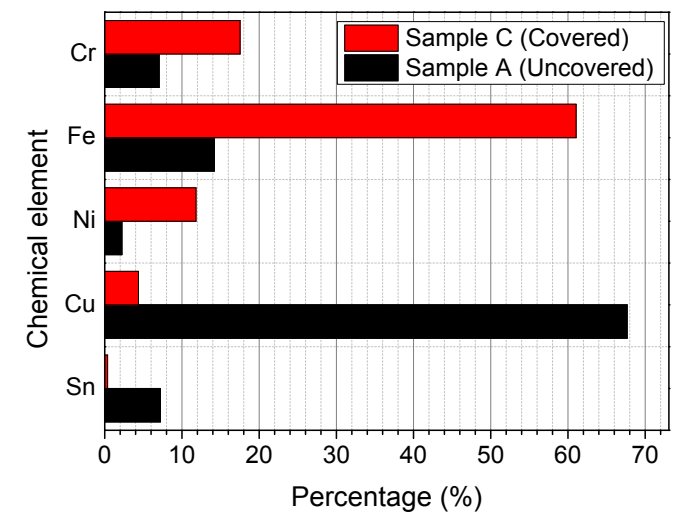

Fig. 16. The chemical elements percentage of the QR-code area on Sample A and Sample C.

\section{Conclusion}

This paper has demonstrated a new approach to implant non-removable anticounterfeiting safety features with a tagging material, different from the build material, into the inaccessible positions on AM processed metallic components based on a proprietary multiple material SLM system. Three samples with the QR code containing special information were fabricated successfully. A sound metallurgical bonding with some porosity was revealed at the $316 \mathrm{~L} / \mathrm{Cu} 10 \mathrm{Sn}$ material interface. The infrared thermography result indicated that this inspection method was able to identify the QR-code on the part surface based on the thermal radiation signal differences caused by the material composition variation between the Cu10Sn and 316L, while it may be interfered by the noises caused by the surface texture difference, including the part surface roughness. On the other hand, digital X-ray images could effectively identify the embedded tags. Heavier tagging material atomic weight and thicker tag material layer would contribute to higher contrast in digital X-ray images. XRF method was able to detect the tagging material on the surface or close to the surface. The detection range was in a millimeter scale. 
The digital X-ray imaging has been found to be the most promising nondestructive method to inspect the embedded security geometric features in metallic components, while X-ray fluorescent spectra can be used for the identification of key chemical compositions of the tagging material against the surrounding materials. The criteria to design the X-ray detectable tagging features are : a) The tagging material should have a distinct atomic weight difference from that of the main building material, that has a fundamental influence on the X-ray imaging result. The larger atomic weight difference is, the better X-ray imaging resolution and contrast will be. So copper alloy, cobaltchromium alloy, tungsten, all of which are suitable for SLM, are promising tagging material candidates for the main SLM building materials including steel, titanium, nickel, and aluminum and related alloys. Material compatibility and working environment should also be taken into account when choosing the tagging material. b) Tags should be imbedded with the relatively thin layer of cover by the component material as the X-ray imaging resolution decreases substantially as the barrier thickness increases. The cover layer thickness would be ideally less than $3 \mathrm{~mm}$. c) The tagging X-ray imaging resolution and contrast can be further improved via increasing the tagging feature thickness and optimizing the X-ray imaging parameters including X-ray tube accelerating voltage, tube current, and exposure time. The recommended tagging material thickness is between $0.2-2 \mathrm{~mm}$.

Multiple material SLM technology provides a new possibility for embedding security features at the inaccessible positions of the AM components, for instance the internal surface of the hollow turbine blade, in manufacturing processes. One could even employ this technology to add the anti-counterfeiting features in conventional manufacturing processes. It could be integrated with the blockchain technology to ensure the produced objects are appropriately certified. Such features could also be used to record the part full life cycle information, including manufacturing, inspection, maintenance and recycles.

One of the challenges affecting the application of the present technology is how to quickly authenticate the part. As the heavy metal elements in stainless steel have stronger absorption to radiation photons, compared with non-metal and light alloy material, e.g. AlSi10Mg, while the working power of the normal hand-held X-Ray radiation detecting devices is limited to low level due to safety issues. Therefore, the embedding security material for components having a high material density should be further investigated to reduce the requirement on detector radiation intensity to achieve a sufficient feature recognition resolution. On the other hand, the need of high cost tagging detection equipment and the high skills of using the equipment may deter some of counterfeiters. 


\section{Acknowledgement}

The University of Manchester is gratefully acknowledged for the Ph.D. scholarship awarded to Mr. Chao Wei. The authors would also like to thank Test and Inspection Center of Shanghai Aerospace Precision Machinery Institute, China, for their assistance in the sample non-destructive inspection.

\section{References}

[1] I. Gibson, D.W. Rosen, B. Stucker, Additive Manufacturing Technologies, 2010. doi:10.1007/978-1-4419-1120-9.

[2] M. Yampolskiy, W.E. King, J. Gatlin, S. Belikovetsky, A. Brown, A. Skjellum, Y. Elovici, Security of Additive Manufacturing: Attack Taxonomy and Survey, Addit. Manuf. 21 (2018) 431-457. doi:10.1016/j.addma.2018.03.015.

[3] M. Khorram Niaki, F. Nonino, The Value for Business and Operations Strategy-The Management of Additive Manufacturing: Enhancing Business Value, in: M. Khorram Niaki, F. Nonino (Eds.), Springer International Publishing, Cham, 2018: pp. 91-129. doi:10.1007/978-3319-56309-1_4.

[4] C.-C. Yeh, Trend Analysis for the Market and Application Development of 3D Printing, Int. J. Autom. Smart Technol. 4 (2014) 1-3. doi:10.5875/ausmt.v4i1.597.

[5] G. Mattsson, Anti-counterfeiting concerns of the vehicle manufacturing sector, J. Intellect. Prop. Law Pract. 10 (2015) 280-284. doi:10.1093/jiplp/jpv036.

[6] F. Panga, A.D. Mchopa, The Impact of Trading Counterfeited Vehicle Spare Parts across the Local Supply Chain : Case of Moshi Municipality, Eur. J. Bus. Manag. 6 (2014) 189-195.

[7] AIA, Counterfeit Parts : Increasing Awareness and Counterfeit Parts : Increasing Awareness and, Aerosp. Ind. Assoc. Am. Inc. (2011).

[8] K. Zile, R. Strazdina, Blockchain use cases and their feasibility, Appl. Comput. Syst. 23 (2018) 12-20. doi:10.2478/acss-2018-0002.

[9] K. Zile, R. Strazdina, Blockchain Use Cases and Their Feasibility, Appl. Comput. Syst. 23 (2018) 12-20. doi:https://doi.org/10.2478/acss-2018-0002.

[10] EUIPO, 2017 Situation Report on Counterfeiting and Piracy in the European Union, Eur. Union Intellect. Prop. Off. (2017).

[11] N. Gupta, F. Chen, N.G. Tsoutsos, M. Maniatakos, ObfusCADe: Obfuscating Additive Manufacturing CAD Models Against Counterfeiting: Invited, Proc. 54th Annu. Des. Autom. Conf. 2017. (2017) 82:1--82:6. doi:10.1145/3061639.3079847.

[12] F. Chen, G. Mac, N. Gupta, Security features embedded in computer aided design (CAD) solid models for additive manufacturing, Mater. Des. 128 (2017) 182-194.

doi:10.1016/j.matdes.2017.04.078.

[13] O. Ivanova, A. Elliott, T. Campbell, C.B. Williams, Unclonable security features for additive manufacturing, Addit. Manuf. 1 (2014) 24-31. doi:10.1016/j.addma.2014.07.001.

[14] Z.C. Kennedy, D.E. Stephenson, J.F. Christ, T.R. Pope, B.W. Arey, C.A. Barrett, M.G. Warner, Enhanced anti-counterfeiting measures for additive manufacturing: coupling lanthanide nanomaterial chemical signatures with blockchain technology, J. Mater. Chem. C. 5 (2017) 9570-9578. doi:10.1039/C7TC03348F.

[15] J. Straub, Physical security and cyber security issues and human error prevention for 3D 
printed objects: detecting the use of an incorrect printing material, (2017) 102200K. doi:10.1117/12.2264578.

[16] A. Adel, The effectiveness of Product Codes in Marketing, Procedia - Soc. Behav. Sci. 175 (2015) 12-15. doi:10.1016/j.sbspro.2015.01.1168.

[17] F. Chen, G. Mac, N. Gupta, Security features embedded in computer aided design (CAD) solid models for additive manufacturing, Mater. Des. 128 (2017) 182-194. doi:https://doi.org/10.1016/j.matdes.2017.04.078.

[18] F. Chen, Y. Luo, N.G. Tsoutsos, M. Maniatakos, K. Shahin, N. Gupta, Embedding Tracking Codes in Additive Manufactured Parts for Product Authentication, Adv. Eng. Mater. 0 (2018) 1800495. doi:10.1002/adem.201800495.

[19] N. Gupta, Embedded security elements for digital models used in additive manufacturing, US Patent App. 15/710,723, 2017.

[20] H. Gong, H.K. Rafi, T. Starr, R. Stucker, Effect of defects on fatigue tests of as-built TI-6AL-4V parts fabricated by selective laser melting, SFF 2012. (2012) 499-506.

[21] K. Rekedal, D. Liu, Fatigue Life of Selective Laser Melted and Hot Isostatically Pressed Ti-6Al-4v Absent of Surface Machining, in: 56th AIAA/ASCE/AHS/ASC Struct. Struct. Dyn. Mater. Conf., American Institute of Aeronautics and Astronautics, 2015. doi:doi:10.2514/6.2015-0894.

[22] H. Kim, Z. Liu, W. Cong, H. Zhang, Additively-Manufactured AISI 4140 Low Alloy Steel, (2017). doi:10.3390/ma10111283.

[23] C. Scott, InfraTrac Successfully Applies Anti-Counterfeit Technology to 3D Printed Metal Parts, 3D Print. (2016).

[24] J. Mazumder, D. Dutta, N. Kikuchi, A. Ghosh, Closed loop direct metal deposition: art to part, Opt. Lasers Eng. 34 (2000) 397-414. doi:https://doi.org/10.1016/S0143-8166(00)00072-5.

[25] S.M. Thompson, L. Bian, N. Shamsaei, A. Yadollahi, An overview of Direct Laser Deposition for additive manufacturing ; Part I : Transport phenomena, modeling and diagnostics, Addit. Manuf. 8 (2015) 36-62. doi:10.1016/j.addma.2015.07.001.

[26] M. Jolly, A. Prabhakar, B. Sturzu, K. Hollstein, R. Singh, S. Thomas, P. Foote, A. Shaw, Review of Non-destructive Testing (NDT) Techniques and their Applicability to Thick Walled Composites, Procedia CIRP. 38 (2015) 129-136. doi:10.1016/j.procir.2015.07.043.

[27] G.L. Workman, P.O. Moore, A.S. for N. Testing, Nondestructive Testing Overview, American Society for Nondestructive Testing, 2012.

[28] E. Herderick, Additive manufacturing of metals: A review, Mater. Sci. Technol. Conf. Exhib. 2011, MS T'11. 2 (2011) 1413-1425.

[29] A. Vyatskikh, S. Delalande, A. Kudo, X. Zhang, C.M. Portela, J.R. Greer, Additive manufacturing of 3D nano-architected metals, Nat. Commun. (2018). doi:10.1038/s41467-018-03071-9.

[30] I.G. David W Rosen, Brent Stucker, Additive manufacturing technologies, Springer, Boston, MA, 2010.

[31] C. Wei, L. Li, X. Zhang, Y.-H. Chueh, 3D Printing of Multiple Metallic Materials by Selective Laser Melting, CIRP Ann. Manuf. Technol. (2018).

[32] C.A. Terrazas, S.M. Gaytan, E. Rodriguez, D. Espalin, L.E. Murr, F. Medina, R.B. Wicker, Multimaterial metallic structure fabrication using electron beam melting, Int. J. Adv. Manuf. Technol. (2013) 33-45. doi:10.1007/s00170-013-5449-0.

[33] Z.H. Liu, D.Q. Zhang, S.L. Sing, C.K. Chua, L.E. Loh, ScienceDirect Interfacial characterization of SLM parts in multi-material processing : Metallurgical diffusion between $316 \mathrm{~L}$ stainless steel 
and C18400 copper alloy, Mater. Charact. 94 (2014) 116-125.

[34] S. Kumar, J.-P. Kruth, Effect of bronze infiltration into laser sintered metallic parts, Mater. Des. 28 (2007) 400-407. doi:https://doi.org/10.1016/j.matdes.2005.09.016.

[35] D. Uzunsoy, I.T.H. Chang, P. Bowen, Fracture behaviour of selective laser sintered Rapidsteel 2.0 under static and dynamic loading, Mater. Sci. Technol. 19 (2003) 897-901. doi:10.1179/026708303225004350.

[36] I. Gibson, D. Rosen, B. Stucker, Additive Manufacturing Technologies, 2013. doi:10.1520/F2792-12A.2.

[37] P.G. Klemens, R.K. Williams, Thermal conductivity of metals and alloys, Int. Met. Rev. 31 (1986) 197-215. doi:10.1179/imtr.1986.31.1.197.

[38] J.R. Davis, Metals Handbook, 1998. doi:10.1007/s13398-014-0173-7.2.

[39] M.-H. Hong, B. Min, T.-Y. Kwon, The Influence of Process Parameters on the Surface Roughness of a 3D-Printed Co-Cr Dental Alloy Produced via Selective Laser Melting, Appl. Sci. 6 (2016) 401. doi:10.3390/app6120401.

[40] A. Kinnear, I. Yadroitsev, I. Yadroitsava, Multi Material Powder Delivering Systems for Selective Laser Melting, Interim. 14 (2015) 11-23.

[41] O. Helen, F.B. Eng, Additive Manufacturing of Aluminium-Metal Matrix Composite developed through Mechanical Alloying, (2016).

[42] G.H. Meng, B.Y. Zhang, H. Liu, G.J. Yang, T. Xu, C.X. Li, C.J. Li, Vacuum heat treatment mechanisms promoting the adhesion strength of thermally sprayed metallic coatings, Surf. Coatings Technol. 344 (2018) 102-110. doi:10.1016/j.surfcoat.2018.03.010.

[43] X. Hao, J. Gu, N. Chen, W. Zhang, X. Zuo, 3-D Numerical analysis on heating process of loads within vacuum heat treatment furnace, 2008. doi:10.1016/j.applthermaleng.2007.12.007.

[44] E. Van Der Aa, J. Fokkens, K. Van Thoor, M. Church, J. Van Der Laan, Finite Element Modelling of Temperature Profiles, Distortions and Residual Stresses due to TIG Welding, 2002.

[45] F.P. Incropera, D.P. DeWitt, T.L. Bergman, A.S. Lavine, Fundamentals of Heat and Mass Transfer, 2007. doi:10.1073/pnas.0703993104.

[46] I. Honeywell,, G.G. Gubareff, Thermal Radiation Properties Survey: A Review of the Literature, Honeywell Research Centre, Minneapolis-Honeywell Regulator Company, 1960.

[47] M.A. Laughton, D.F. Warne, Electrical engineer's reference book, Newnes, 2003. https://books.google.co.uk/books?id=SYSCAQAACAAJ.

[48] G.R. Liu, S.S. Quek, FEM for Heat Transfer Problems, 2014. doi:10.1016/B978-0-08-0983561.00012-6.

[49] R. Siegel, J. Howell, Thermal Radiation Heat Transfer, 1971.

[50] C. Da Wen, I. Mudawar, Modeling the effects of surface roughness on the emissivity of aluminum alloys, Int. J. Heat Mass Transf. 49 (2006) 4279-4289.

doi:10.1016/j.ijheatmasstransfer.2006.04.037.

[51] U. Fano, Penetration of X- and Gamma Rays to Extremely, J. Res. Natl. Burea u Stand. 5 (1953) 95-122.

[52] J. Rumble, Handbook of Chemistry and Physics, CRC Press, 2017.

[53] G. T.Barnes, Contrast and Scatter in X-ray Imaging, RadioGraphics. 11 (1991) 307-323.

[54] D.F. Jackson, D.J. Hawkes, X-RAY ArIENUATION COEFFICIENTS OF ELEMENTS AND MIXTURES, Phys. Rep. 3 (1981) 169-233.

[55] R.B. Roof, X-Ray Absorption Coefficients of Thorium, Uranium, and Plutonium - Experimental 
Determination and THeoretical Interpretation, Phys. Rev. 113 (1959) 820-825.

[56] B. Abidi, M. Mitckes, M. Abidi, J. Liang, F. Hall, Grayscale enhancement techniques of $x$-ray images of carry-on luggage, 5132 (2003).

[57] M. Rajinikannan, A. Nagarajan, N. Vallileka, Contrast Improvement on Various Gray Scale Images Together With Gaussian Filter and Histogram Equalization, 1 (2013) 60-64.

[58] Y. Zhang, W.B. Jia, R. Gardner, Q. Shan, X.L. Zhang, G. Hou, H.P. Chang, A distance correction method for improving the accuracy of particle coal online X-ray fluorescence analysis - Part 1 : Theoretical dependence of XRF intensity on the distance, Radiat. Phys. Chem. 147 (2018) 118121. doi:10.1016/j.radphyschem.2017.07.005.

[59] E.C. Geil, R.E. Thorne, Correcting for surface topography in X-ray fluorescence imaging, J. Synchrotron Radiat. 21 (2014) 1358-1363. doi:10.1107/S160057751401875X.

[60] B. Beckhoff, B. Kanngießer, N. Langhoff, R. Wedell, H. Wolff, Handbook of practical X-ray fluorescence analysis, Springer Science \& Business Media, 2007. 